Earth Interactions - Volume 23 (2019) • Paper No. 3 • Page 1

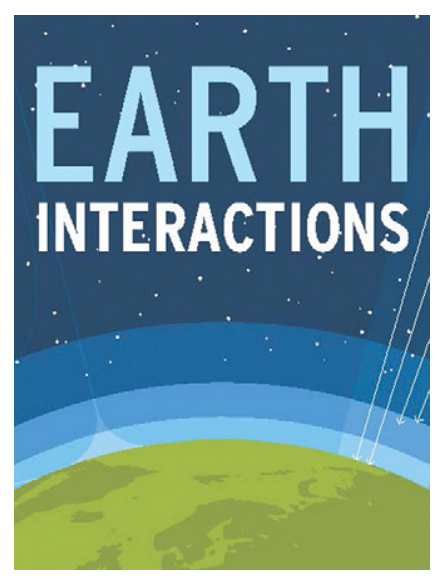

(C) 2019 American Meteorological Society. For information regarding reuse of this content and general copyright information, consult the AMS Copyright Policy (www.ametsoc.org/PUBSReuseLicenses).

\title{
Automated Satellite-Based Landslide Identification Product for Nepall
}

\section{Jessica V. Fayne ${ }^{\text {a }}$}

Department of Geography, University of California, Los Angeles, Los Angeles, California

\section{Aakash Ahamed}

Department of Geophysics, Stanford University, Stanford, California

\section{Justin Roberts-Pierel}

Department of Physics and Astronomy, University of South Carolina, Columbia, South Carolina

\section{Amanda C. Rumsey}

Department of Geography, U.S. Census Bureau, Suitland, Maryland

\section{Dalia Kirschbaum, Ph.D.}

Hydrologic Sciences Laboratory, Code 617, NASA Goddard Space Flight Center Greenbelt, Maryland

Received 24 September 2017; in final form 25 September 2018

\footnotetext{
${ }^{a}$ Corresponding author: Jessica V. Fayne, jfayne@g.ucla.edu
} 
Earth Interactions - Volume 23 (2019) • Paper No. 3 • Page 2

\begin{abstract}
Landslide event inventories are a vital resource for landslide susceptibility and forecasting applications. However, landslide inventories can vary in accuracy, availability, and timeliness as a result of varying detection methods, reporting, and data availability. This study presents an approach to use publicly available satellite data and open-source software to automate a landslide detection process called the Sudden Landslide Identification Product (SLIP). SLIP utilizes optical data from the Landsat-8 Operational Land Imager sensor, elevation data from the Shuttle Radar Topography Mission, and precipitation data from the Global Precipitation Measurement mission to create a reproducible and spatially customizable landslide identification product. The SLIP software applies change-detection algorithms to identify areas of new bare-earth exposures that may be landslide events. The study also presents a precipitation monitoring tool that runs alongside SLIP called the Detecting Real-Time Increased Precipitation (DRIP) model that helps to identify the timing of potential landslide events detected by SLIP. Using SLIP and DRIP together, landslide detection is improved by reducing problems related to accuracy, availability, and timeliness that are prevalent in the state of the art for landslide detection. A case study and validation exercise in Nepal were performed for images acquired between 2014 and 2015. Preliminary validation results suggest $56 \%$ model accuracy, with errors of commission often resulting from newly cleared agricultural areas. These results suggest that SLIP is an important first attempt in an automated framework that can be used for mediumresolution regional landslide detection, although it requires refinement before being fully realized as an operational tool.
\end{abstract}

KEYWORDS: Land surface; Geographic information systems (GIS); Remote sensing

\title{
1. Introduction
}

Landslide inventories are critical for creating and evaluating susceptibility maps, determining relationships between landslide occurrences and triggering events, and informing emerging prediction techniques (Kirschbaum et al. 2009). However, the availability, accuracy, extent, and applicability of landslide inventories can vary widely depending on the location, compilation methodology, and distribution. As a result, landslide inventories suffer from underreporting at both regional and global scales (Petley et al. 2007; Castellanos Abella and van Westen 2007; Kirschbaum et al. 2015). Significant gaps in available landslide information additionally contribute to the shortcomings of landslide inventories due to the lack of routine global monitoring or cataloging systems, such as those available for hurricanes and earthquakes (Kirschbaum et al. 2009).

There are several standard approaches for generating landslide inventories. Some catalogs are generated from news reports, other media, and personal communication (Petley 2012; Kirschbaum et al. 2010, 2015). While these inventories provide global coverage of landslide activity with dates of occurrence, the reliance on media reports can result in uneven spatial and temporal accuracy due to reporting biases and underreporting in more remote areas. Another challenge to reporting is that landslides that occur secondary to primary disasters, like hurricanes or flooding, frequently go unreported since impacts are often reported with the primary disaster (Guzzetti 2000). Event or regional inventories use field surveys, aerial photography, airborne lidar, or other high-resolution satellite data to 
Earth Interactions • Volume 23 (2019) • Paper No. 3 • Page 3

map landslides (Brardinoni et al. 2003; Schulz 2004; Xu et al. 2015). While these methods can accurately delineate landslide events and extent across a study region, in many of these inventories, there is little information on the timing of these events, which can impede the applicability of these data for use in dynamic modeling studies. Additionally, landslide detection using high-resolution imagery and digital elevation model (DEM) methods can be hampered by the availability of or access to data, particularly if imagery needs to be purchased from a commercial vendor. Both of these approaches rely on manual digitization and mapping, which is extremely time consuming and is prone to user error.

Publicly available remote sensing data present a practical method to supplement existing landslide inventories with spatial and temporal information across large regions. Visual image interpretation (Speight 1977; Rib and Liang 1978), computational analysis of passive optical imagery (Landsat, high-resolution commercial imagery), and computational analysis techniques leveraging synthetic aperture radar data (Guzzetti et al. 2012; Behling et al. 2016) have all been used successfully for landslide identification.

Visual image interpretation has become more common with the growing availability of high-resolution imagery and open-source software but is subjective, resource intensive, and time consuming due to manual digitization and interpretation. Furthermore, the timing of landslide events is often imprecise with this method. Multispectral image analysis is a popular technique in landslide detection (Cheng et al. 2004; Nichol and Wong 2005a,b; Martha et al. 2016) because of the 1) additional spectral information content of multispectral imagery, 2) accessibility and free cost of many multispectral sensors (NASA LP DAAC 2016), and 3) opportunity for automation to reduce human inputs and errors. These techniques can limit reporting biases and reduce the time and resources required for event detection (Guzzetti et al. 2012). Spectral landslide detection using multispectral satellite imagery platforms has been demonstrated by a number of studies (Lee and Lee 2006; Weirich and Blesius 2007; Martha et al. 2010; Li et al. 2013). Semiautomated, high-resolution change-detection methods for landslide identification have also been explored previously (Hölbling et al. 2015). In contrast with methods requiring the visible range of the electromagnetic spectrum, interferometric synthetic aperture radar (InSAR) detects surface deformation by using phase differencing and has been an effective technique for landslide identification (Singhroy et al. 1998; Czuchlewski et al. 2003; Farina et al. 2006; Zhao et al. 2012; Tantianuparp et al. 2013). Other methods using radar coherence measure the correlation of the heights of locally varying elevations to identify rough texture. Changes in the coherence and polarimetry will readily pinpoint surface changes (Plank et al. 2016; Casagli et al. 2017; Mondini 2017). While these are incredibly useful features for landslide identification, radar data can be expensive and are typically not as readily available as shorter-wavelength multispectral imagery, rendering this method resource intensive and subject to data availability.

The present study focused on the utilization of multispectral image analysis techniques in order to automate the identification and feature extraction of landslides and changes in bare earth. The motivations for this research are to provide a fast and free method to support analyst work in updating or complementing landslide inventories and also to provide a "first guess" of where landslides may occur without the use of proprietary data or image classification software. Nepal 


\section{Study Area: Nepal}
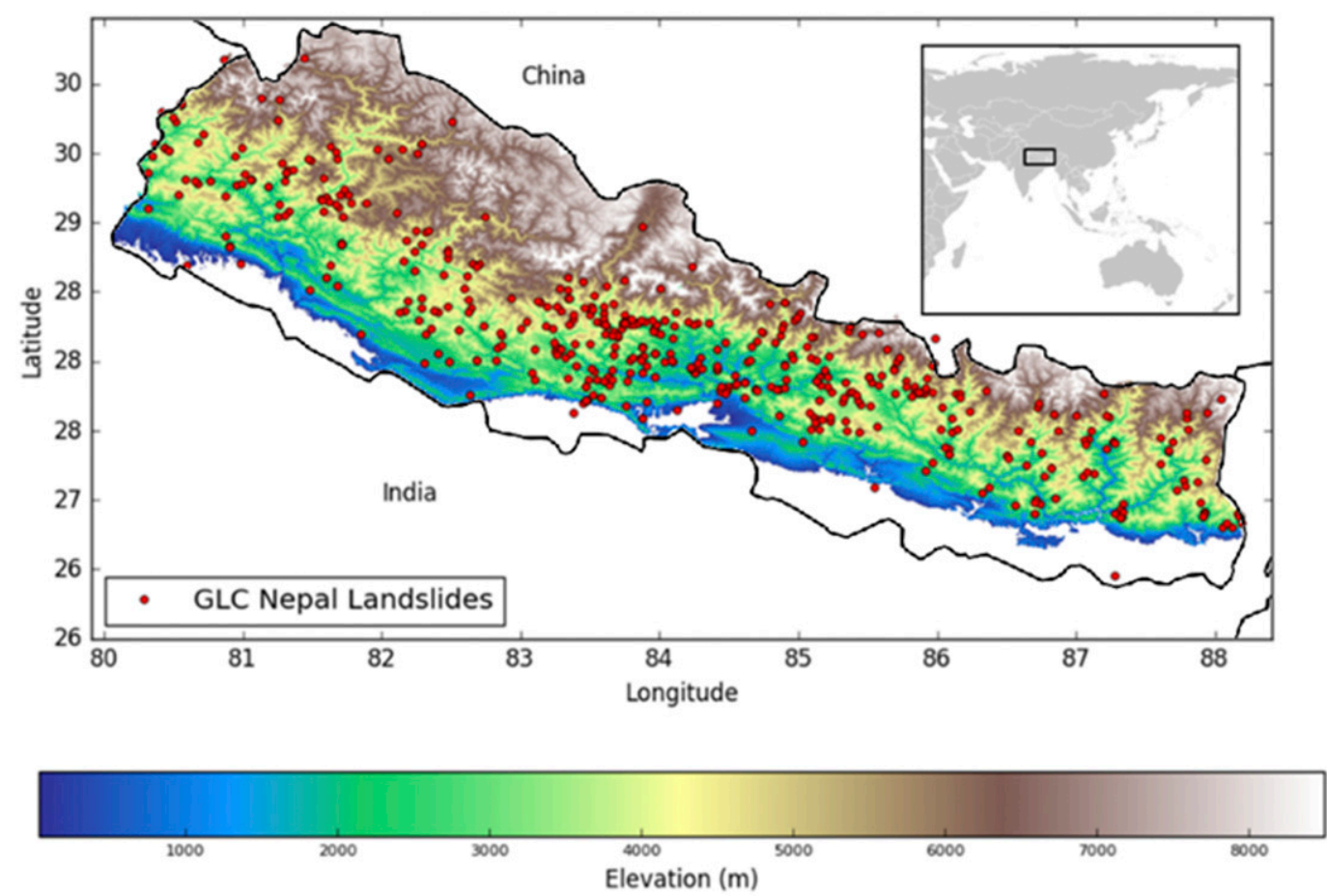

Figure 1. The Nepal study area shows dramatic elevation changes from the southern area bordering India to the northern region bordering China. Landslides from the GLC (Kirschbaum et al. 2015) from 2007 to 2016 are shown in red to demonstrate the widespread distribution of landslides in the region.

was chosen as a case study because of the prevalence of landslide hazards in the region as well as the availability of validation datasets. Nepal and the Greater Himalayan region (Figure 1) are highly susceptible to landslides resulting from mountainous topography, active seismicity, and strong seasonal monsoon rains. The region annually experiences hundreds to thousands of fatalities and millions of dollars in losses from landslide events (Dahal and Hasegawa 2008; Petley et al. 2007). As a result, this region would significantly benefit from additional, publicly available landslide inventories that can be used to improve susceptibility and hazard mapping as well as to support disaster response following a major triggering event.

This study presents a two-sided approach to landslide detection using imagery to identify extent and precipitation data to identify the timing of the landslide. Using Landsat-8 imagery (NASA LP DAAC 2016) and infrastructure from the Open Science Data Cloud (Grossman et al. 2012), a system was developed to test the feasibility of automated landslide detection using spectral band analysis and ancillary data. The Sudden Landslide Identification Product (SLIP) takes advantage of spectral properties of vegetation, slope, land-cover type, and soil moisture in 
Earth Interactions • Volume 23 (2019) • Paper No. 3 • Page 5

biweekly (16 day) time steps to identify new areas of bare-earth exposure that may represent landslide events. To identify the likely timing of potential landslide events, the Detecting Real-Time Increased Precipitation (DRIP) model leverages NASA's Global Precipitation Measurement (GPM) precipitation data to provide a more precise temporal window of occurrence for each potential event. Section 2 reviews the SLIP and DRIP model methods and data sources used, and section 3 discusses validation procedures. Section 4 outlines the results and discussion of the model impact and applicability. Section 5 provides a conclusion with ideas for future research.

\section{Data and method}

SLIP was developed to test the feasibility of automating landslide detection using open-source imagery and without the use of proprietary classification software. Because a predominant triggering mechanism for landslides is rainfall (Petley et al. 2005), this study also explored the development of precipitation-monitoring tools running alongside SLIP to gain insight on local precipitation thresholds necessary for landslides to occur. The Python (programming language) scripts for SLIP and DRIP are available at https://github.com/NASADEVELOP/DRIP-SLIP.

\subsection{Data}

SLIP combines multiple visible and infrared channels from publicly available satellite platforms to approximate visible landscape changes. Topographic slope and soil moisture are also considered to constrain the locations of potential change. Landsat-8 provides updated reflectance data at 30-m spatial resolution every 16 days with five bandwidths in the visual spectrum and six bandwidths in the infrared spectrum. Spectral bands from the red, near infrared, and shortwave infrared (SWIR) were used in this study to identify potential landslide scars automatically.

The slope is calculated from a DEM, and low slopes are masked out in a method described in section 2.2 to limit errors of commission in flat areas where landslides are unlikely, such as riverbeds, which may have similar red reflectance and moisture characteristics. The DEM was created by filling in remaining voids from the "Void Filled" 30-m-resolution Shuttle Radar Topography Mission (SRTM) DEM (USGS SRTM 2001; NASA LP DAAC 2014a, 2015) with the Advanced Spaceborne Thermal Emission and Reflection Radiometer (ASTER) DEM (NASA LP DAAC 2001). The transition between the ASTER and the SRTM data regions was smoothed by first aggregating the spatial resolution to $90 \mathrm{~m}$ and then downsampling the resolution back to $30 \mathrm{~m}$ using bilinear resampling. This produces a smoother transition between DEMs, as was done by Gallant et al. (2011) and Robinson et al. (2014).

A 500-m land-cover map from the International Geosphere-Biosphere Programme (IGBP) derived from the Moderate Resolution Imaging Spectroradiometer (MODIS) sensor (MCD12Q1 2012; NASA LP DAAC 2014a,b) was used as a mask to eliminate agriculture and urban areas that often experience similar changes in soil moisture and vegetation to that of a landslide. As a reflection of the 500-m spatial resolution from IGBP, it is expected that the masked-out areas may be overestimated in some regions relative to the 30-m datasets. 
Earth Interactions • Volume 23 (2019) • Paper No. 3 • Page 6

\subsection{The SLIP algorithm}

SLIP inspects reflectance values and identifies significant changes using four thresholds: 1) reflectance increases in the red wavelength band $4(655 \mathrm{~nm})$, which may indicate bare-earth exposure; 2) changes in the SWIR bands 5 and 7 (860 and $2200 \mathrm{~nm}$ ), which indicate changes in soil moisture; 3) steep slopes as identified by a DEM, which limit identifications to steep topography; and 4) a land-cover mask applied to limit errors of commission in known agricultural areas. Using the Landsat data, "percent red change" is calculated from a difference between dates in the bands at $655 \mathrm{~nm}$. The most recent date is the "current" image, which has clouds flagged as no data. The "composite" image is a cloud-free composite of previous dates of imagery to ensure as much of the scene as possible can be analyzed and not ignored because of current or historical cloud cover.

Changes in the red band are calculated using the equation

$$
\% \text { Red Change }=\left(\frac{\mathrm{R} 655 \mathrm{~nm}_{\text {Current }}-\mathrm{R} 655 \mathrm{~nm}_{\text {Composite }}}{\mathrm{R} 655 \mathrm{~nm}_{\text {Composite }}}\right) \times 100 .
$$

Equation (1) is applied to each pixel in the latest Landsat scene. Areas that show at least a $40 \%$ increase in red reflectance are flagged and marked " 1 " while all other pixels are marked "0."

SLIP was calibrated from spectral analysis of several landslide events in Nepal by visually identifying landslides and inspecting pixel values for those slides. Analysis of the multispectral Landsat data suggested that increases in red wavelengths (band 4: 640-670 $\mathrm{nm}$ ) best captured the spectral characteristics of landslides and bare-earth exposure in mountainous and forested terrains. However, many landslides are much smaller than this in areal extent-no more than 10 Landsat pixels, depending on the shape of the landslide. Therefore, the SLIP model is limited in its ability to detect small landslides.

Vegetation and soil moisture have been estimated using a variety of spectral indices, such as the normalized difference water index (NDWI; Gao 1996) and the normalized multiband drought index (NMDI; Wang and Qu 2007). These indices are effective for measuring drought and flood conditions and their corresponding effects on vegetation. NMDI is sensitive to soil moisture as well as vegetation, making it an ideal means to measure changes in soil moisture over time in areas of sparse vegetation or bare earth, in addition to vegetated areas. Because NMDI was created for MODIS specifications, a modified NMDI variable (mNMDI) was created for this study, focusing on similar sensitivities of infrared and shortwave infrared bands on the Landsat sensor.

The NMDI (for MODIS) is expressed by

$$
\mathrm{NMDI}=\frac{\mathrm{R} 860 \mathrm{~nm}-(\mathrm{R} 1640 \mathrm{~nm}-\mathrm{R} 2130 \mathrm{~nm})}{\mathrm{R} 860 \mathrm{~nm}+(\mathrm{R} 1640 \mathrm{~nm}-\mathrm{R} 2130 \mathrm{~nm})} .
$$

The modified version omits the MODIS 1640-nm shortwave, because the closest band on Landsat-8 is $1610 \mathrm{~nm}$ (band 6), and it demonstrated poor performance for this task. The modified version is as follows, using Landsat- 8 bands 5 and 7 as 860 and $2200 \mathrm{~nm}$, respectively: 
Earth Interactions • Volume 23 (2019) • Paper No. 3 • Page 7

Table 1. Temporal relationships in soil moisture for the three outcomes for this indicator.

\begin{tabular}{llll}
\hline & Today & Historical & Change \\
\hline Outcome 1 & 1 (has moisture) & 0 (no moisture) & $1-0=1$ (new moisture area) \\
Outcome 2 & 1 (has moisture) & 1 (has moisture) & $1-1=0$ (no moisture change) \\
Outcome 3 & 0 (no moisture) & 1 (has moisture) & $0-1=-1$ (moisture decrease) \\
\hline
\end{tabular}

$$
\mathrm{mNMDI}=\frac{\mathrm{R} 860 \mathrm{~nm}-\mathrm{R} 2200 \mathrm{~nm}}{\mathrm{R} 860 \mathrm{~nm}+\mathrm{R} 2200 \mathrm{~nm}} .
$$

Values between -0.2 and 0.2 show higher moisture content, which is clear to see, particularly along water bodies. Using the Spectral Characteristics Viewer from the U.S. Geological Survey (https://landsat.usgs.gov/spectral-characteristics-viewer), the formula can be applied and compared among lawn grass, dry grass, clear water, and rocks/soils. The mNMDI value is 0.5 for lawn grass, 0.3 for dry grass, 0 for clear water, and -0.3 for rocks and dry soils. Mixtures of soils, vegetation, and water center on 0 , with more negative values likely being due to a higher soil mixture and more positive values being due to a higher vegetation mixture. Variations of these mixtures are likely where fresh soils have been revealed after turning over the previous vegetation during landslide events. The change-detection algorithm delineates regions of high moisture and assigns the region a value of 1 ; values outside the region are 0 . Table 1 shows how the biweekly, newest composite, called "today," compares with the previous data called "historical," with three possible outcomes.

Landslide studies using DEMs often use slope thresholds to eliminate errors of commission (Jiménez-Perálvarez et al. 2011). The thresholds and intervals can vary by region, study focus, and DEM resolution. In this model, slope intervals were used to categorize slopes as gentle $\left(0^{\circ}-20^{\circ}\right)$, fairly steep $\left(20^{\circ}-35^{\circ}\right)$, steep $\left(35^{\circ}-45^{\circ}\right)$, very steep $\left(45^{\circ}-60^{\circ}\right)$, and extremely steep $\left(60^{\circ}-90^{\circ}\right)$. The distribution is summarized in Figure 2 for Nepal on the basis of the total area in each category from the DEM 30-m pixels. A slope value of $20^{\circ}$ was used as a minimum threshold for potential landslide initiation points because gentle slopes are less likely to have sudden landslide events. Slope classification values were assigned to each bin to include relative slope information in the final landslide detection, shown in Figure 2.

Values for each flagged pixel (0-1) are summed across the three layers (red reflectance, soil moisture, and slope threshold) to create a raster image with values $0-3$. The reflectance and soil moisture criteria are assigned a value of 0 or 1 , while values for slope are binned into one of five slope classifications $(0.2,0.4,0.6,0.8$, and 1) as summarized in Figure 2. Values less than 1 denote that no criteria were met, values 1-2 indicate that at least one criterion was met, and values 2-3 indicate that both red reflectance and soil moisture criteria were met. Slopes over $20^{\circ}$ are assigned a classification of 0.4 , and slope pixel values greater than or equal to 0.4 are marked as potential landslide initiation areas when combined with reflectance and moisture flags. Total values of 2.4 and above are interpreted as "red looking" areas of increased moisture on a high gradient. An example of this is shown in detail in Figure 3: as the landslide scar shows changes in moisture from the recent rainfall event but no reflectance changes, the newly revealed soil from the landslide 


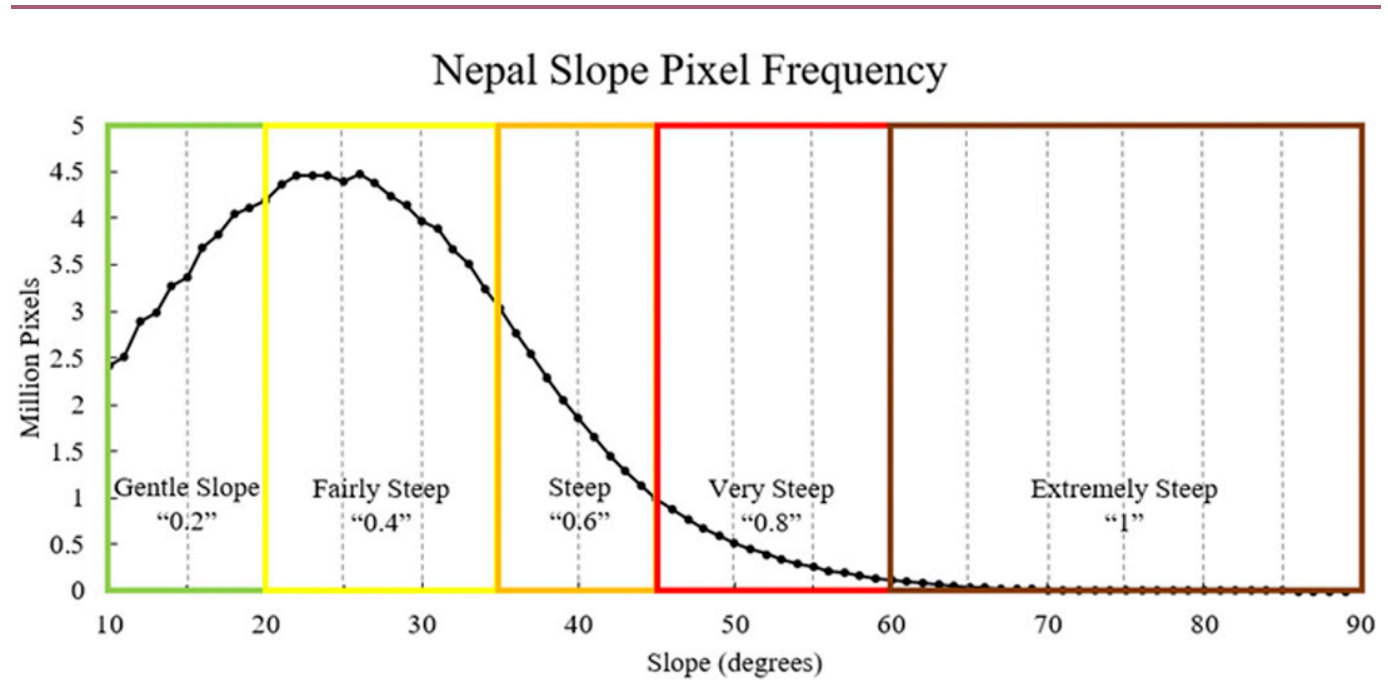

Figure 2. Nepal slope pixel frequency derived from SRTM and ASTER DEMs, with slope classification values used for this study.

shows changes in both reflectance and moisture. The third part of the image demonstrates the red reflectance and moisture changes between the first two Landsat scenes.

After the thresholding was complete, the IGBP MODIS 500-m land-cover map (LP DAAC MCD12Q1 2012) was used as a mask to eliminate agriculture and urban areas that often experience similar changes in soil moisture and vegetation. All pixels that fall within agriculture or urban areas are excluded from the final SLIP output due to frequent erroneous detections by the algorithm.

Updated maps of landslide detections are automatically generated for each tile every 16 days and are saved in a GeoTIFF format. As the file names contain the date and Landsat tile location by path/row, users are able to examine any detection that has been made over a particular area by examining the product file names.

\subsection{The DRIP algorithm}

While SLIP identifies potential landslides at 30-m resolution, the identification is limited by the temporal resolution of the Landsat sensor and the pervasiveness of cloud cover in the study region. Detections can be as frequent as the day that the Landsat image was acquired if the area is cloud free, but they can be limited by up to 3 months during periods of extensive cloud cover, requiring many composited images. If we assume that the SLIP landslide detections are triggered by rainfall and that the peak precipitation during the 16day temporal window between overpasses coincides with landslide occurrence, landslide detections can be identified in finer temporal windows by monitoring continuous precipitation accumulations in the 16-day period between detections from SLIP.

The DRIP tool was developed (Figure 4) to provide suggested dates to correspond to the SLIP landslide detections. Another advantage of DRIP is that it helps 
Earth Interactions • Volume 23 (2019) • Paper No. 3 • Page 9

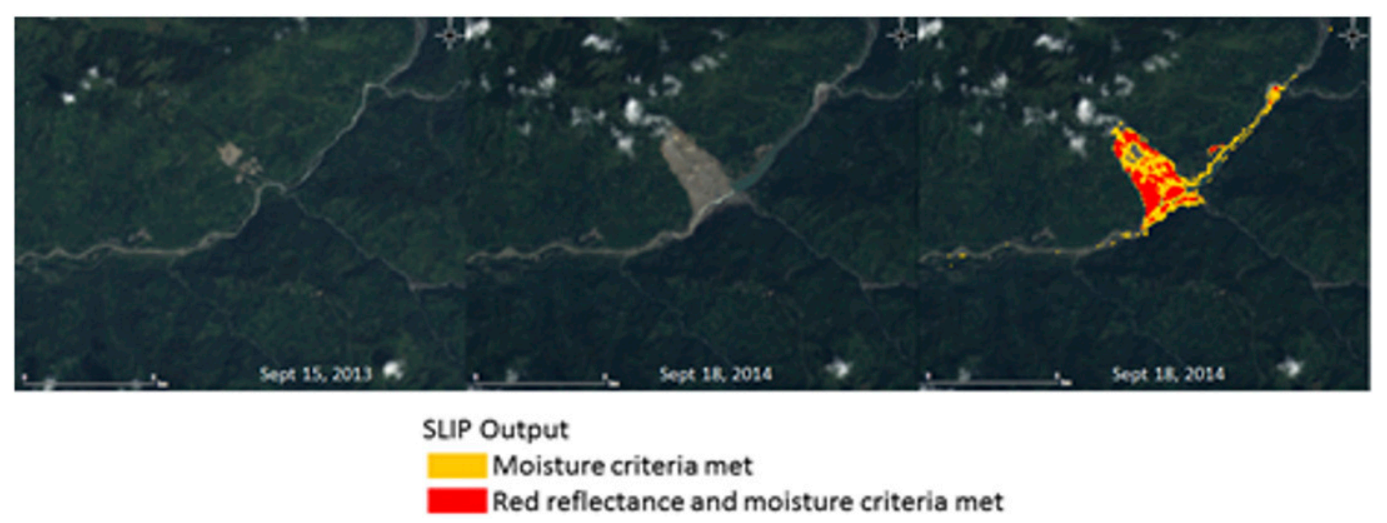

Figure 3. The Jure Sunkoshi Landslide, which occurred on 2 Aug 2014, was used for calibration and testing in earlier iterations of the SLIP algorithm. Here, it is shown (left) prior to (15 Sep 2013) and (center) after(18 Sep 2014) the landslide. (right) The SLIP detection with a Landsat-8 base map is shown from the same 18 Sep image, with the SLIP pixel detection highlighting where the soil moisture criteria (yellow) or both red reflectance and soil moisture criteria (red) are met.

to identify extreme rainfall in near-real time and suggest where potential images may be located, as seen in Figure 4.

There have been several research efforts to quantify rainfall thresholds for landslide triggering in the study region (Dahal and Hasegawa 2008; Froehlich and Starkel 1993). In particular, Froehlich et al. (1990) established that in the Himalayan region, small slides and flows can be triggered by between 130 and $150 \mathrm{~mm}$ of accumulated rainfall in a 24-h period and 180-200-mm accumulation in $72 \mathrm{~h}$. For larger slide events, landslides may be triggered only after exceeding 250 and $350 \mathrm{~mm}$ of rainfall in a $24-$ and $72-\mathrm{h}$ period, respectively. In subsequent

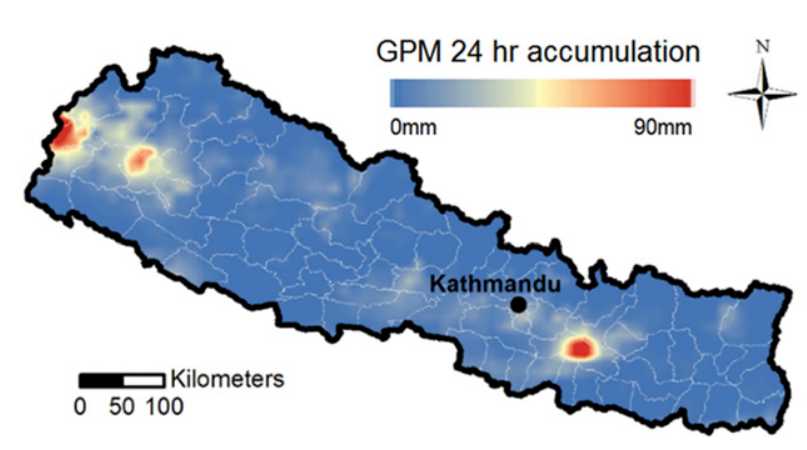

Figure 4. DRIP makes rainfall accumulation maps in 24- (shown here), 48-, and 72-h moving windows, which can be compared with the 16-day Landsat-8 image revisit time. The maps pinpoint regions where rainfall accumulations exceed established thresholds for rainfall triggered landslides. 
Earth Interactions • Volume 23 (2019) • Paper No. 3 • Page 10

research, Dahal and Hasegawa (2008) identified that 144-mm rainfall accumulation in a 24-h period substantially increased the risk of landslides. Although both of these studies were undertaken using gauge and not satellite data, they do provide a baseline for considering potential triggering thresholds in this region. A study of satellite precipitation products from GPM's predecessor, the Tropical Rainfall Measuring Mission (TRMM), reveals that orographic precipitation may be underestimated by 5-14 mm (Hashemi et al. 2017). As GPM uses some of the same satellites as TRMM in the multisatellite merged product, it is expected that GPM and TRMM will have similar biases. To use the GPM data in this analysis, we present lower thresholds than were established in the gauge studies.

To associate the intense rainfall events to probable landslides, satellite precipitation data are gathered in near-real time from the Global Precipitation Measurement mission Integrated Multisatellite Retrievals for GPM (IMERG) "Early" product (Huffman et al. 2015), which is available in half-hourly time steps and $0.1^{\circ}$ spatial resolution with a latency of $4 \mathrm{~h}$. DRIP collects the half-hourly IMERG data in a moving 16-day window to accommodate the SLIP output and constructs rainfall accumulations in 24-, 48-, and 72-h moving windows within the 16-day span, using threshold values of 145,170 , and $195 \mathrm{~mm}$, respectively.

To suggest the landslide event date within the 16-day window, DRIP selects the 24-, 48-, and 72-h data that exceed the established rainfall thresholds. When there are multiple dates that exceed the rainfall threshold, the largest rainfall event is chosen. While it is uncertain which of the major storms contributed to the landslide, it is likely that the landslide may be associated with the passage of the storm, either during or after the event. Similarly, where the 24-h thresholds are met, the additional 48- and 72-h thresholds are not considered, even if the threshold is reached for the longer duration.

The pixels with the precipitation values exceeding the thresholds from the 24-, 48-, and 72-h windows are combined into one product, with a separate raster data layer containing metadata of the original dates that contributed to the combined product. To use the DRIP outputs with SLIP, the combined thresholds are given a flag of " 2 " in a similar manner to the three SLIP flags. The coordinates of each pixel extent are used to assign the additional DRIP flag to the SLIP output, as the spatial resolution of the GPM precipitation is much coarser than the Landsat SLIP product.

When the " 2 " flag is added to the SLIP product, SLIP-DRIP total values above 4 have corresponding precipitation values exceeding the DRIP threshold and will have specified dates and times for the extreme rainfall that may suggest a trigger for the potential landslide(s). This process can offer insight into the potential timing of the landslides detected as well as on regional precipitation thresholds that may result in slope failures.

\subsection{Automation and preprocessing}

SLIP and DRIP require the open-source libraries NumPy (http://numpy.org) for processing raster arrays and GDAL (http://gdal.org) for reading, writing, and archiving geospatial data. The SLIP program preprocesses Landsat-8 data before performing change-detection analyses and uses an external program to download Landsat-8 data (Hagolle et al. 2016). The workflow for all the SLIP and DRIP 

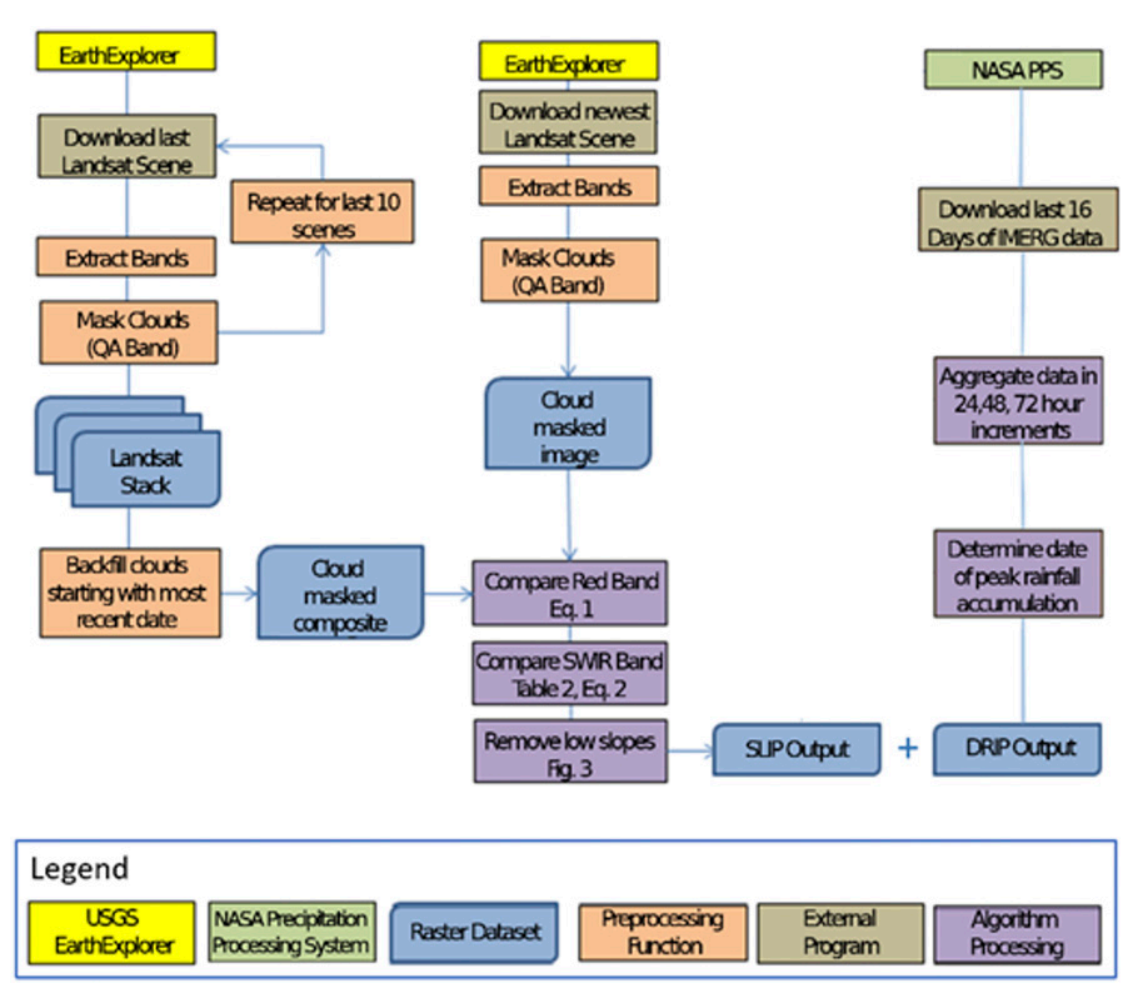

Figure 5. Workflow showing data-processing architecture of SLIP and DRIP.

components can be found in Figure 5. The SLIP and DRIP documentation (https:// github.com/NASA-DEVELOP/DRIP-SLIP) details the list of package dependencies, as well as installation instructions. The SLIP and DRIP algorithms were tested using a server hosted by the Open Science Data Consortium (Grossman et al. 2012).

\subsubsection{SLIP automation}

The SLIP program can download new Landsat-8 scenes from USGS Earth Explorer (https://earthexplorer.usgs.gov/; NASA LP DAAC 2016) each day as scenes are made available. When a new Landsat scene is available in the study area, the program proceeds to the preprocessing and change-detection stages. The Landsat- 8 satellite captures images of the Nepal and Himalayan region every 16 days at 30-m resolution. For this application, SLIP downloads Landsat scenes (paths 139-144; rows 39-41) as they become available.

When each new scene is downloaded, the red band (band 4: $655 \mathrm{~nm}$ ), SWIR (band 7: $2200 \mathrm{~nm}$ ), near-infrared (band 5: $860 \mathrm{~nm}$ ), panchromatic band 8, and quality assurance (QA) bands are extracted and stored in a temporary directory. Each Landsat tile in the study region has a local repository of the previous 10 scenes at that tile. To address issues of persistent cloud cover, compositing tasks mask out cloud pixels, replacing missing data with data from the previous 10 
Earth Interactions • Volume 23 (2019) - Paper No. 3 • Page 12

scenes to maximize cloud-free observations. Cloud identification procedures mask pixels based on the Landsat-8 QA band and a 96\% reflectance threshold in the panchromatic band. All pixels flagged as clouds are replaced with corresponding cloud-free pixels from the previous scenes, beginning with the most recent. This process iterates until either all pixels in the current scene are cloud free or all 10 scenes have been used in the backfill. The newest image is then compared with the composited image.

\subsubsection{DRIP automation}

The DRIP program downloads the GPM IMERG data in near-real time through the NASA Precipitation Processing System FTP server (ftp://jsimpson.pps.eosdis. nasa.gov/). The processing latency for the half-hourly GPM IMERG dataset is approximately 4-6h from observation. These data are an "early run" initial processing of the data without gauge calibration (Huffman et al. 2015) and are not considered "research grade," which are produced more than a month after the satellite observation. For the near-real-time application of landslide identification and dating, it is deemed more important to have a more rapid intake of available precipitation data as they are available.

The FTP server provides the GPM data on a global grid in HDF file format. As data are made available, they are downloaded and then "subset" to the region as a GeoTIFF file, and accumulations are created for the 24-, 48-, and 72-h moving windows. Because intense, short-duration precipitation is more likely to cause landslides in this region than are lower-intensity, longer-duration accumulations (Froehlich et al. 1990; Froehlich and Starkel 1993; Dahal and Hasegawa 2008; Petley 2012), the 24-h accumulation carries more significance than the 48- and 72-h accumulations. The Python script uses this priority to create a set of three raster images for the 16-day period matching the Landsat SLIP output. The first image represents points at which the rainfall thresholds have been triggered with the triggering values, the second "image" contains the date as a pixel value, and the third raster is the triggering flag that works directly with the SLIP outputs.

\section{Validation}

The SLIP model outputs were validated to assess SLIP's landslide identification capabilities on a regional scale within Nepal. Two SLIP detection raster maps were selected for five Landsat tiles covering Nepal (Figure 6). For each tile, one raster

falling during the monsoon season (June-September) and another raster falling outside the monsoon season (October-May) were selected for validation. In total, 10 dates were selected for validation.

To prepare the SLIP data for validation, SLIP detection images were masked to only retain pixels with values greater than 2.4 , representing areas that exceeded the three previously mentioned thresholds and areas that met the land-cover condition. Using GIS software, each raster was converted to a polygon. A $60-\mathrm{m}$ buffer was then applied to each polygon to cluster discrete polygons into larger landslide events. This technique ensures that neighboring detected pixels with a small gap in detection will be considered to be the same landslide event. As there may be hundreds of landslide detections that fit the criteria, which is more than can be 


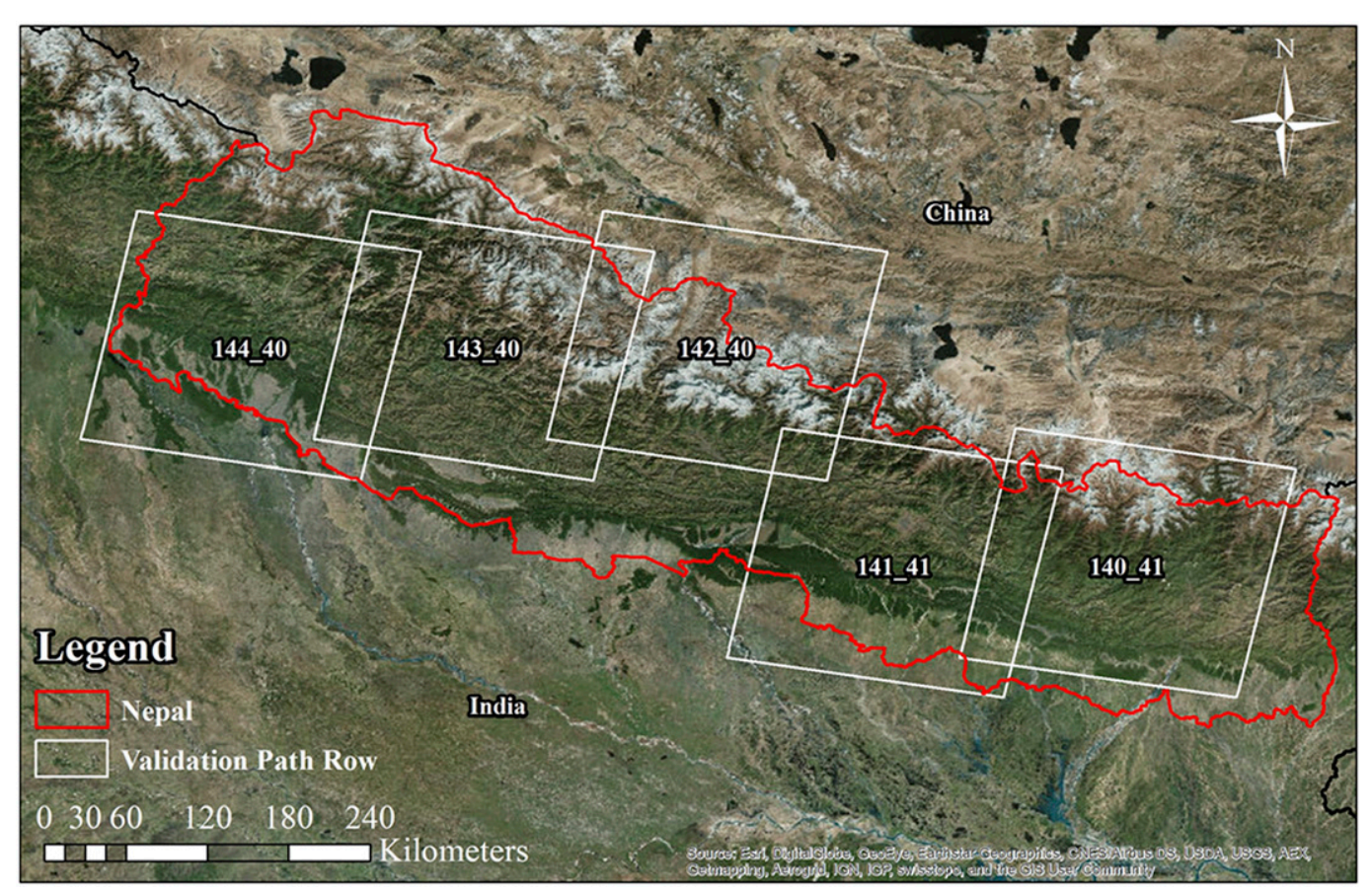

Figure 6. The Landsat tiles used for validation of SLIP. For validation, two SLIP detections were selected for each tile to represent monsoon (June-October) and dry-season conditions.

efficiently validated manually, a sample of $10 \%$ of the landslide detections was extracted from each of the 10 buffered shapefiles for validation.

The landslide event polygons were validated using a Google Earth scene following the date of the detection. Google Earth Pro (desktop version) was used to reference the landslides by entering the coordinates of the potential landslides into the search and modifying the time slider to match a time near the estimated landslide event. Two analysts visually assessed each of the landslide event polygons independently and assigned them to an appropriate classification category. The nine classification categories assigned for an event included "landslide" occurring in a forest or as a result of glacier melt along with the no-landside categories terrace, barren, agriculture, mountainside/no vegetation change, riverbed, and urban; the category unidentifiable was assigned if the surface could not be clearly seen from the Google Earth reference imagery. If a SLIP event was classified as landslide, the event was assigned a value of 1 representing a positive landslide detection; a no-landslide event was assigned a value of 0 , representing a false positive landslide detection; and an unidentifiable event was also assigned a value of 0 because of the inability to positively identify a landslide. The nonlandslide classifications help to quantify deficiencies in the algorithm, particularly when there are high errors of commission for a certain type of nonlandslide.

A confidence rating was assigned to each SLIP event detection on the basis of the combined assessment of the analysts. A rating of "high confidence" was given to detections for which both reviewers agreed that a positive detection occurred, a 

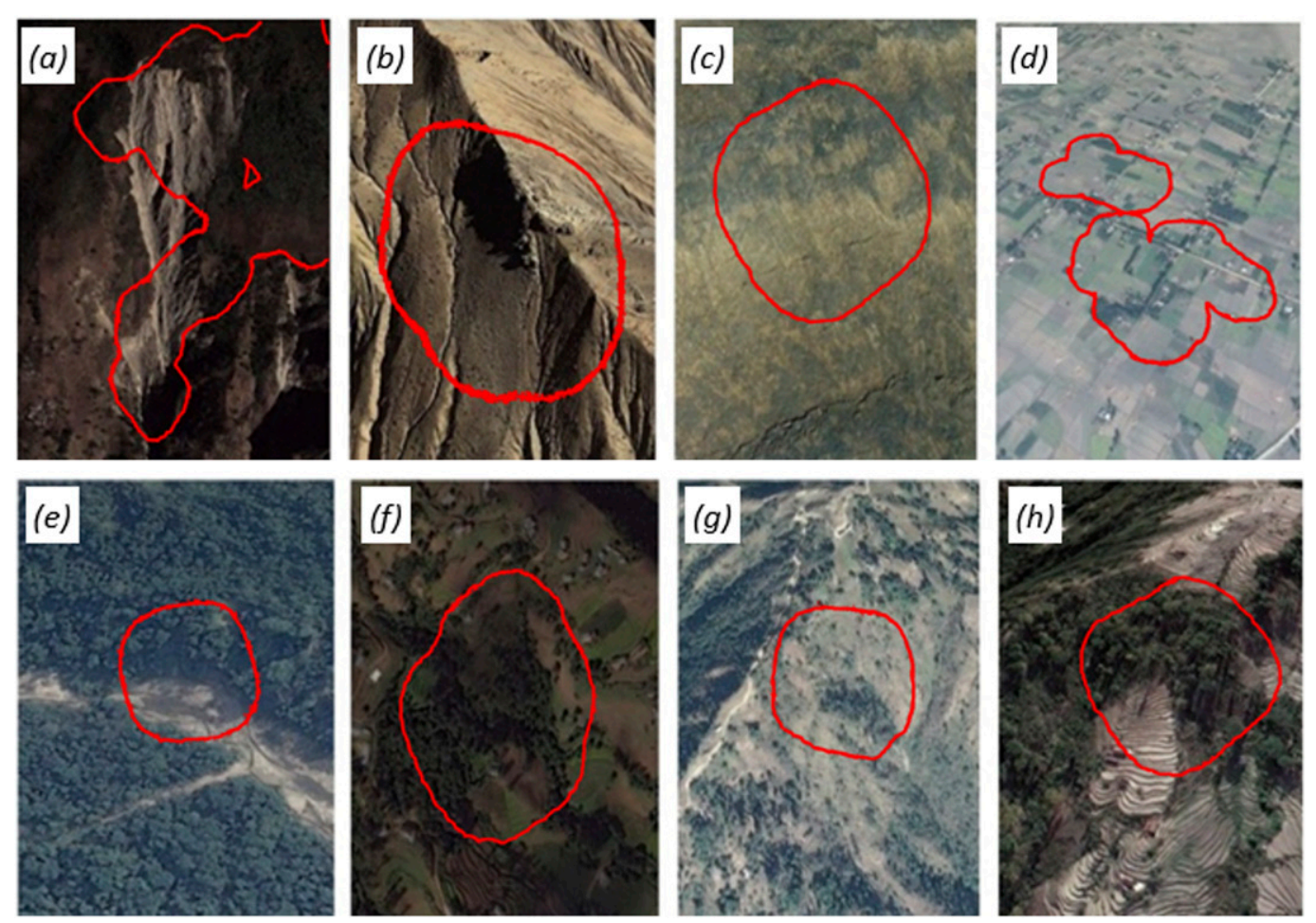

Figure 7. Example validation results for each classification category: (a) forest landslide, (b) glacier-melt landslide, (c) barren, (d) agriculture, (e) riverbed, (f) urban, (g) mountainside/no vegetation change, and $(h)$ terrace.

rating of "low confidence" was given to detections for which only one of the two reviewers believed that a positive detection occurred, and a rating of "no confidence" was given to the detections for which both reviewers agreed that the detection was a false detection.

\section{Results and discussion}

The SLIP model outputs were validated using $15-\mathrm{m}$ resolution or higher in Google Earth imagery to assess landslide identification capabilities on a regional scale within Nepal (Figure 7). The SLIP classification results are displayed inTable 2. In the 10 validation scenes, SLIP detected high-confidence landslides with accuracies ranging from $12 \%$ to $56 \%$. The average high-confidence accuracy over Nepal is $27 \%$. When low-confidence landslides are included in the assessment, detection accuracies increase significantly, ranging from $32 \%$ to $83 \%$. This averages out to an overall accuracy of $56 \%$ for "combined detection" over the entire region.

Multiple regional characteristics could influence inconsistencies in results among tiles. The SLIP algorithm is designed to detect areas that experience changes in vegetation and soil moisture that exceed a certain slope threshold. Because Nepal is predominantly mountainous, agricultural and terraced areas 
Earth Interactions - Volume 23 (2019) • Paper No. 3 • Page 15

Table 2. Validation results for the sampled SLIP detections. High-confidence landslides are detections in which both reviewers classified an event as a landslide. Low-confidence landslides are detections in which one of the two reviewers classified an event as a landslide. Tiles with majority agricultural land cover are in boldface type and are found to have a lower overall accuracy.

\begin{tabular}{|c|c|c|c|c|c|c|c|c|c|}
\hline Path & Row & Yearday & Year & $\begin{array}{l}\text { Monsoon } \\
\text { season }\end{array}$ & $\begin{array}{l}\text { No. of } \\
\text { validated } \\
\text { potential } \\
\text { landslide } \\
\text { detections }\end{array}$ & $\begin{array}{l}\text { High- } \\
\text { confidence } \\
\text { landslides } \\
(\%)\end{array}$ & $\begin{array}{c}\text { Low- } \\
\text { confidence } \\
\text { landslides } \\
(\%)\end{array}$ & $\begin{array}{c}\text { Combined } \\
\text { landslide } \\
\text { confidence } \\
(\%)\end{array}$ & $\begin{array}{c}\text { Commission } \\
\text { errors }\end{array}$ \\
\hline 140 & 41 & 254 & 2014 & Y & 83 & 57 & 26 & 83 & 36 \\
\hline 140 & 41 & 81 & 2015 & $\mathrm{~N}$ & 91 & 42 & 30 & 69 & 52 \\
\hline 141 & 41 & 245 & 2014 & $\mathbf{Y}$ & 22 & 13 & 19 & 31 & 19 \\
\hline 141 & 41 & 88 & 2015 & $\mathbf{N}$ & 99 & 26 & 33 & 59 & 73 \\
\hline 142 & 40 & 268 & 2014 & $\mathrm{Y}$ & 71 & 36 & 25 & 61 & 45 \\
\hline 142 & 40 & 79 & 2015 & $\mathrm{~N}$ & 96 & 28 & 38 & 67 & 68 \\
\hline 143 & 40 & 227 & 2014 & $\mathrm{Y}$ & 70 & 21 & 33 & 55 & 55 \\
\hline 143 & 40 & 38 & 2015 & $\mathrm{~N}$ & 70 & 18 & 53 & 71 & 57 \\
\hline 144 & 40 & 234 & 2014 & $\mathbf{Y}$ & 69 & 18 & 12 & 29 & 56 \\
\hline \multirow[t]{2}{*}{144} & 40 & 77 & 2015 & $\mathbf{N}$ & 54 & 14 & 18 & 32 & 46 \\
\hline & & & & Avg & & 27 & 29 & 56 & \\
\hline
\end{tabular}

commonly experience soil moisture changes due to irrigation and vegetation changes due to harvesting. These areas are often found on slopes exceeding the current SLIP threshold. The land-cover classification criterion was added to the product to eliminate false positive detections in urban and agricultural areas, but due to the coarse resolution of publicly available land-cover maps, agriculturerelated false detections persist. The tiles that fall within the agricultural region of Nepal (path/row 144/40 and path/row 141/41 are highlighted in Table 2) have much lower combined landslide confidence accuracies than other tiles covering mountainous regions and uninhabited regions of Nepal. The agricultural tiles have combined landslide confidence accuracies ranging from $29 \%$ to $58 \%$, whereas mountainous tiles have accuracies ranging from $54 \%$ to $83 \%$.

Errors of commission can also result from unmasked clouds that may match the soil and brightness criteria of SLIP. Though cloud masking and buffering techniques are included in the model, some clouds can be difficult to distinguish from the land surface, particularly in areas of snowcapped mountains. Future advances in cloud-masking algorithms and the incorporation of thermal imagery could serve to enhance the cloud mask and further reduce errors of commission.

SLIP was also analyzed to detect performance variations due to seasonality. Of the five tiles analyzed during validation, four showed a 4\%-14\% increase in highconfidence landslide detection performance during the monsoon season (Table 2). When used without DRIP, SLIP is likely to perform better during the monsoon season due to rainfall-induced landslide occurrence, as extreme rainfall events are the primary driver of landslide occurrences in the country. Combining DRIP with SLIP has the potential to decrease the number of false detections during the monsoon and dry seasons.

Because the dates are not precisely defined in the imagery alone, existing landslide databases such as the Global Landslide Catalog (GLC; Kirschbaum et al. 2010), International Disaster Database (Sapir and Misson 1992), and Durham Fatal 


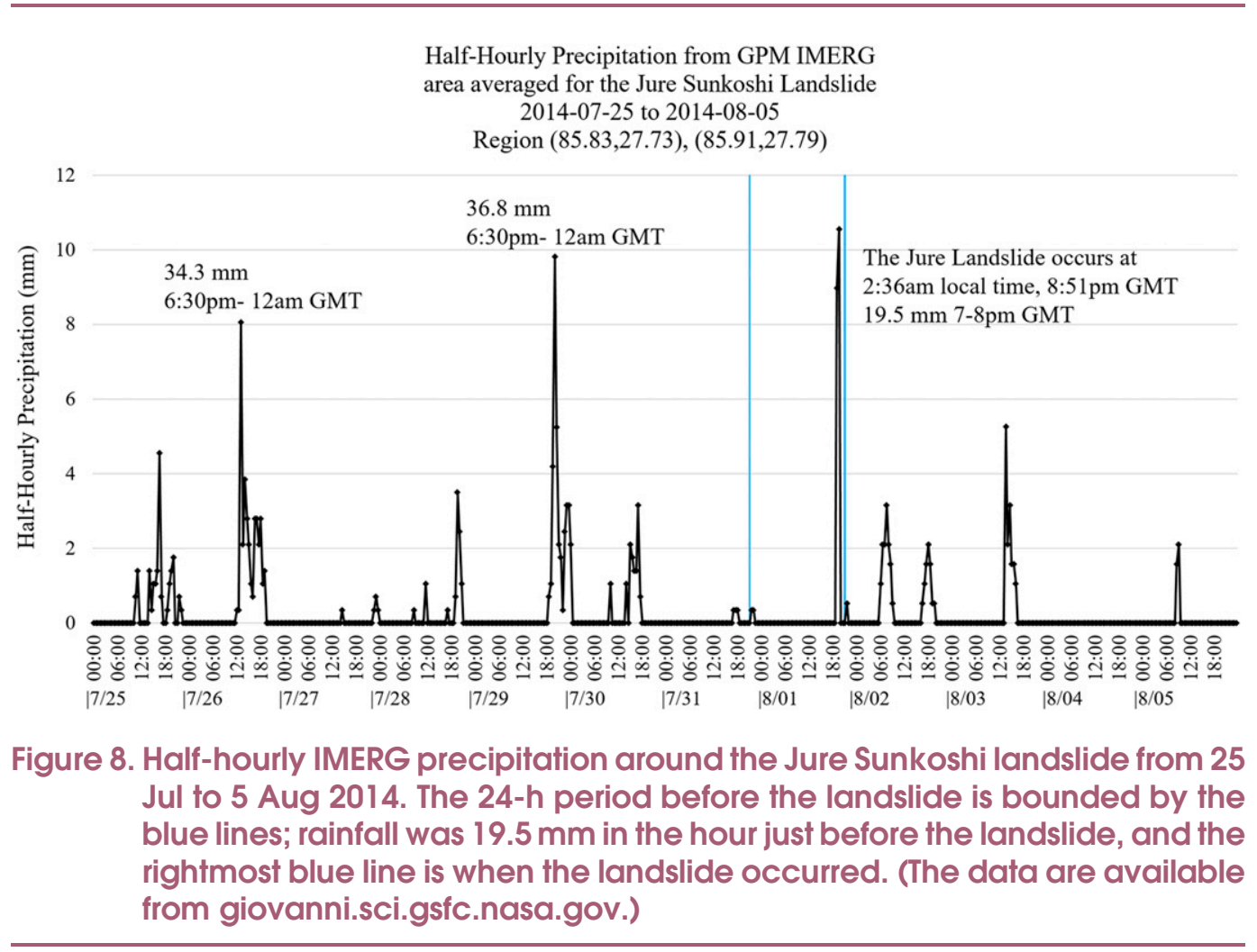

Landslide Database (Petley 2012) can be used to validate DRIP. To this end, the DRIP validation requires dates to be associated with each landslide event, with a preference given to event entries with precise times. However, because of reporting biases affecting the dates and times in existing inventories, a more constricted catalog with a minimal date-based bias will be compiled for Nepal from the previously mentioned sources as well as additional sources. The new compilation database is currently in progress and is not available for validation of the current work, but it will be discussed in the validation of future improvements to the SLIP and DRIP algorithms. Using a more comprehensive database will allow more rigorous analysis using inventories. Once complete, the DRIP time series for each pixel surrounding the respective landslide event will be used to estimate the date and time of the landslide. The estimated time from DRIP can then be compared with the actual time from the reported landslide.

The DRIP precipitation time series for the Jure Sunkoshi Landslide featured in Figure 3 is shown in Figure 8 and highlights the intense precipitation in the hours leading up to the event. The rainfall events leading up to the slide were spread out as major storms every few days, culminating in one rainfall event with $38 \mathrm{~mm}$ of rain falling in $1 \mathrm{~h}$. This is significantly higher precipitation than the average $2 \mathrm{~mm} \mathrm{~h}^{-1}$ for the pixel.

Limitations of the proposed method stem from calibration and sensitivity of the spectral bands used within the SLIP algorithm as well as limitations of the validation datasets. Data from previous Landsat satellites were evaluated to determine 
Earth Interactions • Volume 23 (2019) - Paper No. 3 • Page 17

if these data can be used to construct a longer record. However, analysis of Landsat-7 and Landsat-5 indicated that the bands used in these satellites diverged too much from those available from Landsat-8. The sensitivity of the algorithm has been developed to function with characteristics that are common globally, but it has so far only been tested in the Nepal region. Calibration for SLIP was performed for a small group of landslides in Nepal and therefore is limited by the quality and availability of the catalog for this region. Validation of this model is also subject to uncertainties due to the analysts' interpretation of landslides within the area and the availability of imagery within Google Earth. If the algorithm detected a landslide but there are not sufficient multitemporal views or look angles from high-resolution imagery to confirm the landslide event, the validation may be biased. Potential differences between analysts' visual classifications were addressed by requiring two assessments for each SLIP detection; however, the limited availability of highresolution imagery at the temporal and spatial scales necessary for robust assessment, even from Google Earth, hinders the accuracy of the "ground truth" for purposes of classifying land cover types. If one considers using this model for other regions, the SLIP model would need to be calibrated and tested with high-quality landslide inventory information because of the presence of different land-cover types, terrain, and atmospheric effects such as trace cloud cover and haze that could not be removed by the Landsat cloud mask and atmospheric correction.

There are also issues regarding the high level of false alarms in the current algorithm. As discussed above, the false alarms can result from physical phenomena such as seasonal vegetation changes, riverbeds, agricultural lands, and urban areas. Additional false alarms may result from sensor and algorithm sensitivities such as seasonal brightness changes, cloud and edge artifacts from the multiday composite process, and sensor abnormalities (such as scan errors). As a result, this algorithm still requires manual validation of potential landslide detections before they should be considered as true landslide points.

\section{Conclusions}

Two automated tools, SLIP and DRIP, have been developed to identify potential location and timing of newly triggered landslides seen from Landsat-8 imagery using spectral thresholding algorithms and precipitation data from GPM. These tools have the ability to map new landslide events and estimate specific dates for the landslide occurrence.

The SLIP algorithm demonstrates how publicly available Landsat-8 data can be utilized for automated and rapid detection of potential landslide events. However, the limitations of the current system may impact its applicability or transferability across users or regions. The system detects changes on the surface within areas of high slopes where there is an indication that the ground is wet. Therefore, the algorithm requires adjustment to the local elevation and slope characteristics in order to identify the crowns or initiation points that are on regionally different gradients. In addition, this algorithm may not be sensitive to seismically triggered landslides where moisture is not a significant cause for the event. Slow-moving creep events that occur on more gradual slopes and shallow debris flows with narrow widths but long runouts are also less likely to be detected because of the masking out of more gradually sloping areas, the $30-\mathrm{m}$ spatial resolution of the Landsat data, and the 
Earth Interactions • Volume 23 (2019) • Paper No. 3 • Page 18

expectation of a drastic reflectance difference between scenes. The Landsat pixel resolution also limits the detection of smaller landslides (less than 30-45 m in width).

SLIP enables automatic landslide identification with the intention to reduce the amount of time required to interpret satellite imagery manually. This method covers larger areas and can digest more imagery relative to supervised classification, which can be useful in the context of research and situational awareness of potentially impacted areas following a major event. The SLIP algorithm requires additional refinement to remove errors from the temporal compositing before it can be fully realized as an operational tool but is an important first attempt in an automated operational framework for medium-resolution regional landslide detection. The DRIP algorithm can be similarly used as a standalone product to aid in the manual identification of major precipitation events in near-real time that may cause landslides and flooding events. More testing of regional suitability and applicability is required before these tools can be implemented for disaster relief applications.

Acknowledgments. This research was funded by a grant from the NASA Applied Sciences Program as a part of the NASA DEVELOP National Program. We thank NASA DEVELOP and all of the Himalayan Disasters Team members and advisors at NASA Goddard Space Flight Center for supporting and guiding the research. We also thank Dr. John Bolten, who is the lead science advisor for NASA DEVELOP at Goddard Space Flight Center, and Mr. Thomas Stanley, whose expertise in landslide mapping contributed useful feedback on our methods. The International Centre on Integrated Mountain Development (ICIMOD) also supported the NASA DEVELOP effort through collaboration, data sharing, and student participation. This work made extensive use of the server provided by Open Science Data Cloud (OSDC), which was used in all stages of the initial development, testing, and validation of the SLIP and DRIP methods.

\section{References}

Behling, R., S. Roessner, D. Golovko, and B. Kleinschmit, 2016: Derivation of long-term spatiotemporal landslide activity-A multi-sensor time series approach. Remote Sens. Environ., 186, 88-104, https://doi.org/10.1016/j.rse.2016.07.017.

Brardinoni, F., O. Slaymaker, and M. A. Hassan, 2003: Landslide inventory in a rugged forested watershed: A comparison between air-photo and field survey data. Geomorphology, 54, 179196, https://doi.org/10.1016/S0169-555X(02)00355-0.

Casagli, N., and Coauhtors, 2017: Spaceborne, UAV and ground-based remote sensing techniques for landslide mapping, monitoring and early warning. Geoenviron. Disasters, 4, 9, https://doi.org/ 10.1186/s40677-017-0073-1.

Castellanos Abella, E. A., and C. J. van Westen, 2007: Generation of a landslide risk index map for Cuba using spatial multi-criteria evaluation. Landslides, 4, 311-325, https://doi.org/10.1007/ s10346-007-0087-y.

Cheng, K. S., C. Wei, and S. C. Chang, 2004: Locating landslides using multi-temporal satellite images. Adv. Space Res., 33, 296-301, https://doi.org/10.1016/S0273-1177(03)00471-X.

Czuchlewski, K. R., J. K. Weissel, and Y. Kim, 2003: Polarimetric synthetic aperture radar study of the Tsaoling landslide generated by the 1999 Chi-Chi earthquake, Taiwan. J. Geophys. Res., 108, 6006, https://doi.org/10.1029/2003JF000037.

Dahal, R. K., and S. Hasegawa, 2008: Representative rainfall thresholds for landslides in the Nepal Himalaya. Geomorphology, 100, 429-443, https://doi.org/10.1016/j.geomorph.2008.01.014. 


\section{Earth Interactions • Volume 23 (2019) • Paper No. 3 • Page 19}

Farina, P., D. Colombo, A. Fumagalli, F. Marks, and S. Moretti, 2006: Permanent scatterers for landslide investigations: Outcomes from the ESA-SLAM project. Eng. Geol., 88, 200-217, https://doi.org/10.1016/j.enggeo.2006.09.007.

Froehlich, W., and L. Starkel, 1993: The effects of deforestation on slope and channel evolution in the tectonically active Darjeeling Himalaya. Earth Surf. Processes Landforms, 18, 285-290, https://doi.org/10.1002/esp.3290180309.

— E. Eil, I. Kasza, and L. Starkel, 1990: Thresholds in the transformation of slopes and river channels in the Darjeeling Himalaya, India. Mt. Res. Dev., 10, 301-312, https://doi.org/ $10.2307 / 3673492$.

Gallant, J. C., T. Hengl, I. S. Evans, J. P. Wilson, and M. Gould, 2011: Adaptive smoothing for noisy DEMs. Geomorphometry 2011, Redlands, CA, ESRI, 37-40, http://geomorphometry.org/ system/files/Gallant2011 geomorphometry.pdf.

Gao, B., 1996: NDWI-A normalized difference water index for remote sensing of vegetation liquid water from space. Remote Sens. Environ., 58, 257-266, https://doi.org/10.1016/ S0034-4257(96)00067-3.

Grossman, R. L., and Coauthors, 2012: The design of a community science cloud: The open science data cloud perspective. 2012 SC Companion: High Performance Computing, Networking Storage, and Analysis, Salt Lake City, UT, IEEE, https://doi.org/10.1109/ SC.Companion.2012.127.

Guzzetti, F., 2000: Landslide fatalities and the evaluation of landslide risk in Italy. Eng. Geol., 58, 89-107, https://doi.org/10.1016/S0013-7952(00)00047-8.

_ A. C. Mondini, M. Cardinali, F. Fiorucci, M. Santangelo, and K. T. Chang, 2012: Landslide inventory maps: New tools for an old problem. Earth-Sci. Rev., 112, 42-66, https://doi.org/ 10.1016/j.earscirev.2012.02.001.

Hagolle, O., V. Nunes, T. Lampada, M. Mitchell, and A. Tzotsos, 2016: LANDSAT data download. Olivier Hagolle, accessed January 2018, https://github.com/olivierhagolle/ LANDSAT-Download/blob/master/download_landsat_scene.py.

Hashemi, H., M. Nordin, V. Lakshmi, G. J. Huffman, and R. Knight, 2017: Bias correction of longterm satellite monthly precipitation product (TRMM 3B43) over the conterminous United States. J. Hydrometeor, 18, 2491-2509, https://doi.org/10.1175/JHM-D-17-0025.1.

Hölbling, D., B. Friedl, and C. Eisank, 2015: An object-based approach for semi-automated landslide change detection and attribution of changes to landslide classes in northern Taiwan. Earth Sci. Inform., 8, 327-335, https://doi.org/10.1007/s12145-015-0217-3.

Huffman, G. J., D. T. Bolvin, D. Braithwaite, K. Hsu, R. J. Joyce, C. Kidd, E. J. Nelkin, and P. Xie, 2015: NASA Global Precipitation Measurement (GPM) Integrated Multi-satellitE Retrievals for GPM (IMERG). NASA Algorithm Theoretical Basis Doc. Version 4.5, 30 pp., http:// pmm.nasa.gov/sites/default/files/document_files/IMERG_ATBD_V4.5.pdf.

Jiménez-Perálvarez, J. D., C. Irigaray, R. El Hamdouni, and J. Chacón, 2011: Landslide-susceptibility mapping in a semi-arid mountain environment: An example from the southern slopes of Sierra Nevada (Granada, Spain). Bull. Eng. Geol. Environ., 70, 265-277, https://doi.org/ 10.1007/s10064-010-0332-9.

Kirschbaum, D. B., R. Adler, Y. Hong, and A. Lerner-Lam, 2009: Evaluation of a preliminary satellite-based landslide hazard algorithm using global landslide inventories. Nat. Hazards Earth Syst. Sci., 9, 673-686, https://doi.org/10.5194/nhess-9-673-2009.

,$--\longrightarrow$, S. Hill, and A. Lerner-Lam, 2010: A global landslide catalog for hazard applications: Method, results, and limitations. Nat. Hazards, 52, 561-575, https://doi.org/ 10.1007/s11069-009-9401-4.

— T. Stanley, and Y. Zhou, 2015: Spatial and temporal analysis of a global landslide catalog. Geomorphology, 249, 4-15, https://doi.org/10.1016/j.geomorph.2015.03.016.

Lee, S., and M.-J. Lee, 2006: Detecting landslide location using KOMPSAT 1 and its application to landslide-susceptibility mapping at the Gangneung area, Korea. Adv. Space Res., 38, 22612271, https://doi.org/10.1016/j.asr.2006.03.036. 


\section{Earth Interactions • Volume 23 (2019) • Paper No. 3 • Page 20}

Li, Y., G. Chen, B. Wang, L. Zheng, Y. Zhang, and C. Tang, 2013: A new approach of combining aerial photography with satellite imagery for landslide detection. Nat. Hazards, 66, 649-669, https://doi.org/10.1007/s11069-012-0505-x.

Martha, T. R., N. Kerle, V. Jetten, C. J. van Westen, and K. V. Kumar, 2010: Characterising spectral, spatial and morphometric properties of landslides for semi-automatic detection using object-oriented methods. Geomorphology, 116, 24-36, https://doi.org/10.1016/ j.geomorph.2009.10.004.

_ , P. Kamala, J. Jose, K. V. Kumar, and G. J. Sankar, 2016: Identification of new landslides from high resolution satellite data covering a large area using object-based change detection methods. J. Indian Soc. Remote Sens., 44, 515-524, https://doi.org/10.1007/s12524-015-0532-7.

Mondini, A. C., 2017: Measures of spatial autocorrelation changes in multitemporal SAR images for event landslides detection. Remote Sens., 9, 554, https://doi.org/10.3390/rs9060554.

NASA LP DAAC, 2001: AST14DEM: ASTER Digital Elevation Model V003. NASA Land Processes DAAC, accessed July 2018, https://doi.org/10.5067/ASTER/AST14DEM.003.

_ _ 2014a: Data pool. NASA Land Processes DAAC, accessed July 2018, https://lpdaac.usgs.gov/ data_access/data_pool.

_ 2014b: Land cover type yearly L3 global $500 \mathrm{~m}$ SIN grid: MCD12Q1. NASA Land Processes DAAC, accessed July 2018, https://lpdaac.usgs.gov/dataset_discovery/modis/ modis_products_table/mcd12q1.

_ 2015: Shuttle Radar Topography Mission (SRTM) Void Filled. USGS, accessed July 2018, https://lta.cr.usgs.gov/SRTMVF.

_, 2016 , Landsat 8 OLI (Operational Land Imager) and TIRS (Thermal Infrared Sensor). USGS, accessed 1 January 2016, https://lta.cr.usgs.gov/L8.

Nichol, J., and M. S. Wong, 2005a: Satellite remote sensing for detailed landslide inventories using change detection and image fusion. Int. J. Remote Sens., 26, 1913-1926, https://doi.org/ $10.1080 / 01431160512331314047$.

$\longrightarrow$, and $-2005 \mathrm{~b}$ : Detection and interpretation of landslides using satellite images. Land Degrad. Dev., 16, 243-255, https://doi.org/10.1002/ldr.648.

Petley, D. N., 2012: Global patterns of loss of life from landslides. Geology, 40, 927-930, https:// doi.org/10.1130/G33217.1.

— S. A. Dunning, and N. J. Rosser, 2005: The analysis of global landslide risk through the creation of a database of worldwide landslide fatalities. Landslide Risk Management, O. Hungr et al., Eds., Taylor and Francis, 367-374.

— G. J. Hearn, A. Hart, N. J. Rosser, S. A. Dunning, K. Oven, and W. A. Mitchell, 2007: Trends in landslide occurrence in Nepal. Nat. Hazards, 43, 23-44, https://doi.org/ 10.1007/s11069-006-9100-3.

Plank, S., A. Twele, and S. Martinis, 2016: Landslide mapping in vegetated areas using change detection based on optical and polarimetric SAR data. Remote Sens., 8, 307, https://doi.org/ $10.3390 / \mathrm{rs} 8040307$.

Rib, H. T., and T. Liang, 1978: Recognition and identification. Landslide: Analysis and Control, R. L. Schuster and R. J. Krizek, Eds., TRB Special Rep. 176, 34-80.

Robinson, N., J. Regetz, and R. P. Guralnick, 2014: EarthEnv-DEM90: A nearly-global, void-free, multi-scale smoothed, $90 \mathrm{~m}$ digital elevation model from fused ASTER and SRTM data. ISPRS J. Photogramm. Remote Sens., 87, 57-67, https://doi.org/10.1016/ j.isprsjprs.2013.11.002.

Sapir, D. G., and C. Misson, 1992: The development of a database on disasters. Disasters, 16, 74 80, https://doi.org/10.1111/j.1467-7717.1992.tb00378.x.

Schulz, W. H., 2004: Landslides mapped using LIDAR imagery, Seattle, Washington. USGS OpenFile Rep. 2004-1396, 11 pp., https://doi.org/10.3133/ofr20041396.

Singhroy, V., K. E. Mattar, and A. L. Gray, 1998: Landslide characterisation in Canada using interferometric SAR and combined SAR and TM images. Adv. Space Res., 21, 465-476, https://doi.org/10.1016/S0273-1177(97)00882-X. 
Earth Interactions • Volume 23 (2019) • Paper No. 3 • Page 21

Speight, J. G., 1977: Landform pattern description from aerial photographs. Photogrammetria, 32, 161-182, https://doi.org/10.1016/0031-8663(77)90012-6.

Tantianuparp, P., X. Shi, L. Zhang, T. Balz, and M. Liao, 2013: Characterization of landslide deformations in Three Gorges area using multiple InSAR data stacks. Remote Sens., 5, 27042719, https://doi.org/10.3390/rs5062704.

Wang, L., and J. Qu, 2007: NMDI: A normalized multi-band drought index for monitoring soil and vegetation moisture with satellite remote sensing. Geophys. Res. Lett., 34, L20405, https:// doi.org/10.1029/2007GL031021.

Weirich, F., and L. Blesius, 2007: Comparison of satellite and air photo based landslide susceptibility maps. Geomorphology, 87, 352-364, https://doi.org/10.1016/j.geomorph.2006.10.003.

Xu, C., X. Xu, and J. B. H. Shyu, 2015: Database and spatial distribution of landslides triggered by the Lushan, China Mw 6.6 earthquake of 20 April 2013. Geomorphology, 248, 77-92, https:// doi.org/10.1016/j.geomorph.2015.07.002.

Zhao, C., Z. Lu, Q. Zhang, and J. de La Fuente, 2012: Large-area landslide detection and monitoring with ALOS/PALSAR imagery data over Northern California and southern Oregon, USA. Remote Sens. Environ., 124, 348-359, https://doi.org/10.1016/j.rse.2012.05.025.

Earth Interactions is published jointly by the American Meteorological Society, the American Geophysical Union, and the Association of American Geographers. For information regarding reuse of this content and general copyright information, consult the AMS Copyright Policy (www.ametsoc.org/PUBSReuseLicenses). 